\title{
Anlık Sorgu Geri-Getirimi Test Veri Kümesi Hazırlamak İçin Bir Web Aracı
}

\section{A Web Based Tool For Preparing Adhoc Retrieval Test Data}

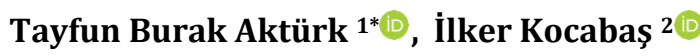 \\ ${ }^{1}$ Manisa Celal Bayar Üniversitesi, Turgutlu Meslek Yüksekokulu, Bilgisayar Teknolojileri Bölümü, Turgutlu, Manisa, \\ TÜRKIYE \\ 2, Ege Üniversitesi, Uluslararası Bilgisayar Enstitüsü, Bornova, İzmir, TÜRKIYE \\ Sorumlu Yazar / Corresponding Author*: tbakturk@hotmail.com
}

Atıfsșekli/How to cite: AKTÜRK,T.B., KOCABAȘ, İ.(2021). Anlık Sorgu Geri-Getirimi Test Veri Kümesi Hazırlamak İçin Bir Web Aracı. DEUFMD, 23(67), 277-284.

$\ddot{0} \mathbf{z}$

Bu çalışmanın amacı, bilgi erişimi alanında yazılı belge derlemleri kullanarak hazırlanan test veri kümeleri için sorgulara karşılık gelen belgelerin alakalı/alakasız yargısının yapılacağı bir web aracı geliștirmektir. Anlık sorgu geri-getirim için test veri kümesi bir belge topluluğu, belirli sayıda sorgular ve bu sorgulara karşıllk gelen alakalı belgeleri içermektedir. Özellikle, belgelerin sorgu hedeflerine uygun olup olmadığının değerlendirilmesi ișlemi oldukça karmașık ve zaman alıcıdır. Sorguların alakalı olduğu belgeleri işaretleme işlemini dijital ortamda gerçekleştirecek bir uygulamaya ihtiyaç vardır. Çünkü çok sayıda belgenin alaka yargısı yapan kullanıcılar tarafından incelenmesi gerekmektedir. Bu çalışmada, TREC'te (Text Retrieval Conference) uygulanan yöntemi temel alarak geliştirilen araç ile bu süreç yönetilebilir hale gelmiştir.

Anahtar Kelimeler: Test veri kümesi, anlık sorgu geri-getirimi, TREC

\begin{abstract}
The main purpose of this study is to develop a web tool, which helps out on making relevant/nonrelevant judgement of documents used in the test datasets prepared for text retrieval. The test dataset for the adhoc retrieval contains a collection of documents, a certain number of queries, and relevant documents corresponding to these queries. Especially, the process of judging whether documents fit query targets or not is quite complex and time consuming. There is a need for an application that will perform the process of marking the documents relevant to the queries in a digital environment. Because a large number of documents need to be examined by users who are concerned with relevance. In this study, this process has become manageable by the tool developed on the basis of the method applied in the TREC (Text Retrieval Conference).
\end{abstract}

Keywords: Test dataset, adhoc retrieval, TREC

\section{Giriş}

Bilgi ve iletişim teknolojilerinin hızla geliştiği günümüz dünyasında, insanların ihtiyaçları ve bu ihtiyaçlara bulunan çözümler farklılık göstermektedir. Hemen her konuda ihtiyaç duyulan bilgi internet ortamında çeşitli 
DEÜ FMD 23(67), 277-284, 2021

sitelerden veya bloglardan elde edilebilmektedir. Bilgi Erișimi (kıs. BE) araçları özellikle web-tabanlı arama motorları en popüler ve en sık kullanılan uygulamalardır.

Yazılı belgeler üzerinde bilgi erişimi işlemi kullanıcının sisteme bir sorgu girmesiyle başlamaktadır. BE sistemi ise ihtiyaç duyulan bilgiyi ifade eden bu sorguya karşılık gelen belgeleri belirli bir alaka ağırlığına göre sıralayarak getirmektedir. Sistemin geri-getirim başarımı erişilen belgelerin ihtiyacı ne ölçüde karşılayabildiğidir.

BE sistemlerinin başarımlarını ölçmek için literatürde birçok [1]-[4] ölçüt bulunmaktadır. Ancak bașarı ölçütünden daha önemli temel konu, bir BE sisteminin nasll test edileceğidir. Cranfield deneyleri [5] ile ortaya konulan bilgi erişimi başarım ölçme test modeli, TREC (Text Retrieval Conference)[6] gibi büyük ölçekli sistemlerin değerlendirilmesi çalıșmalarında kullanılmaktadır.

$\mathrm{Bu}$ çalıșmada TREC test derlemlerinin alaka yargısı yapılma süreci bir web aracı olarak gerçeklenmiştir. İlerleyen bölümlerde ilgili süreç detaylandırılmış; aracın tasarımı, yapısı ve kullanım şekli anlatılmıștır. Türkçe yazılı belgeler üzerinde yapılan BE çalıșmalarını geliştirmek için geçerli ve kapsamlı test veri kümeleri oluşturmak gerekmektedir. İlgili kişilerin bu araca web üzerinden http://www.IR-lab.ege.edu.tr adresinden erișimi mümkündür.

\section{Motivasyon}

Bilgi Erişimi (İng. information retrieval, kıs. BE) iși bir belge topluluğu içinden hedef duyulan bilgi ihtiyacını karşılayan, yani alakalı olan belgelere erișimi verimli hale getirmekle uğraşan bir bilim alanıdır. Bilgi ihtiyacı kullanıcılar tarafından belirli bir yapıda olmayacağı gibi önceden tanımlı bir yapıya uygun olarak da sorgu veya konu başlığı olarak ifade edilebilmektedir. Örnek olarak, sorgular herhangi bir doğal dilde veya mantıksal bir ifade kullanılarak olușturulabilmektedirler.

BE alanındaki ilk çalıșmalar doğal dilde yazılmıș belge topluluklarında metin geri getirimi (İng. Text retrieval) üzerine yapılmıștır. Ancak; ses, müzik, resim ve video belgelerinde erişim gibi [7] alt problemlere de benzer kuramsal alt-yapı ile çözümler bulunmaya çalışılmaktadır. 'Bilgi erişimi' süreci uygulamalarda geri getirim görevi
(İng. retrieval tasks, kıs. GGG) olarak adlandırılan bazı işlevsel farklılıklar göstermektedir. Metin geri getirimi olarak adlandırılan geleneksel BE'nde temel olarak iki geri getirim görevi bulunmaktadır: bunlar anlıksorgu geri getirimi (İng. adhoc retrieval) ve yönlendirme görevi (İng. routing task) olarak adlandırılmaktadırlar. Anlık-sorgu geri getiriminde sabit belge topluluğu kullanılarak değişen sorgular ile erişim hedeflenirken, yönlendirme görevinde ise sabit sorgular ile değișen belge topluluklarına erișim gerçekleştirilmektedir. Her iki görevde de erişim işlemindeki ana odak sistemlerin başarımlarıdır.

$\mathrm{Bu}$ çalışmada temel olarak hedeflenen konu: Bilgi Erişimi (İng. Information Retrieval, kıs. BE) alanında anlık sorgu görevinde yapılan testler için bir veri ve süreç uygulaması geliştirmektir. BE çalışmalarının testlerinde sistemlerin hedeflerine uygun olan veri kümelerine - göreve uygun derlem, sorgu kümesi ve alakalı belge kümesi- ve değerlendirme ölçütlerine ihtiyaç duyulmaktadır[8]. $\quad \mathrm{Bu} \quad$ görevlerdeki farklılıklardan doğan yeni veri kümelerinin hazırlanması ve ilgili ölçütler ile değerlendirilmesi işlemlerinin yönetilmesi oldukça zor ve vakit alıcıdır. Özellikle sorguların alakalı olduğu belgeleri işaretleme işlemini dijital ortamda gerçekleştirecek bir uygulamaya ihtiyaç vardır. Çünkü çok sayıda belgenin hakemler -alaka yargısı yapan kullanıcılartarafından incelenmesi gerekmektedir. $\mathrm{Bu}$ amaçla, çalışmada geliştirilen web-tabanlı yazılım sürecin yönetimini kolaylaştırmakta ve hızlandırmaktadır.

\section{TREC Anlık Sorgu Geri-Getirim Sınama Kümesi Hazırlanma Süreci}

1992 yllından beri düzenlenen TREC (Text Retrieval Conference) çalıștayları A.B.D. Savunma Bakanlığı ve NIST (İng. National Institute of Standards and Technology) tarafından desteklenmektedir. Bu çalıștayların öncelikli hedefi BE yöntemlerinin metin geri getirim alanında büyük ölçekli değerlendirilmesine imkan sağlayacak bir sınama yapısı oluşturulmasıdır. Metin geri getirim sahasındaki araştırmalara katkı vermek üzere, büyük hacimli yazılı belge derlemleri ve BE bașarım değerlendirme yapısına ilișkin standartlar TREC kapsamında oluşturulmaya çalışılmaktadır [6]. Her yıl düzenlenen TREC kapsamındaki bilgi erișimi çalıștaylarında yeni 
görevler ihtiyaçlarına ve kısıtlarına göre belirlenmektedir. Yönlendirme ve anlık-sorgu erișim görevlerinin alt-problemleri olan bu görevlerin her biri "iz" (İng. track) olarak isimlendirilir ve yıllar içinde şekillenerek geliștirilir. Yalnızca bu iki temel görevi içeren ilk iki TREC [9],[10]'ten sonraki yıllarda TREC-1 ve TREC-2'den oluşturulan alt-yapının kuramsal olarak farklı görevler için de uygun olacağı düşünülerek yeni görevler tanımlanmıştır. TREC-3'te [11] eklenen bu yeni iki erişim görevi etkileșimli görev (İng. interactive task) ve İspanyolca görevi (İng. Spanish task) olarak belirtilmiştir. 2007 yılına kadar toplam 27 farklı iz [12] TREC çalıştayları sırasında olușturulmuștur. Güncel olarak ise, "TREC-Covid Challenge"[13] ve "TREC Deep Learning Track"[14] isimli görevler bulunmaktadır. Ancak; Hintçe[15], Çince[16] ve Rusça[17] gibi diller için TREC benzeri forumlar olmasına rağmen, hala Türkçe yazılı metinler için tanımlı bir görev bulunmamaktadır.

TREC izleri bir takım özellikleri önceden belirlenen bir işleyişe uygun olarak gerçekleștirilmektedir. İlk olarak, iz'e özel kullanılacak bir doğal dilde yazılmış belgeler topluluğu, sorgular ve erișim değerlendirme ölçütleri NIST tarafından belirlenmektedir. TREC'te yazılı belge toplulukları derlem, sorgular ise konular olarak adlandirılır ve belgeler ile oluşturulan konular SGML/XML standartlarına göre etiketlenmișlerdir. Ek olarak belgeler ve konular; yapısal (etiketli alanlar), niceliksel ve boyutsal olarak izlere göre değișkenlik göstermektedir. Konu içinde birden fazla etiketli alan bulunmaktadır (anlık-sorgu izinde bunlar title, description, narrative olarak belirlenmiștir.) ve izlere göre bu alanlardan hangisinin kullanılacağı da değişebilmektedir. Başarım değerlendirme ölçütlerinin seçimi ise alaka yargısının işleyişi ile bağıntılı bir süreçtir. Anlık-sorgu görevine sahip izlerde katılımcllar genellikle sistem yürütüm (İng. run) sonuçlarından her sorguya karşılık gelen ilk 1000 (en fazla) belgeyi NIST'e göndermektedirler. Katılımcıların yürütüm sonuçlarındaki belgeler bir havuzda toplanarak hakemler tarafindan belirlenen alaka yargılaması yöntemine göre alakalı/alakasız olarak ișaretlenmektedir [18]. Daha sonra ise sistem bașarımları iz'de belirlenen değerlendirme ölçütlerine göre hesaplanmakta ve katılımcılara ilan edilmektedir. Bu ișlem BE test veri kümesi oluşturma ve değerlendirme sürecidir.

TREC organizasyonlarının süreci Şekil 1'de gösterilmiştir. Süreç katılımcılara sorgu ve derlem kümelerinin sağlanmasıyla başlamaktadır (T0 anı). Sonra, katılımcılar BE sistemlerini verilen sorguları kullanıp, belirlenen derlem üzerinde çalıștırmaktadırlar (T0-T1 arası). BE yürütümlerinden sonra, elde edilen çlktılar TREC tarafından toplanmakta ve bir havuz oluşturularak bütün sonuçlar için alaka yargısı yapılmaktadır (T1-T2 arası). Alaka yargısı yapılan çıktılar sonrasında, sonuçlar açıklanarak bir tartıșma oturumu ile süreç sonlanmaktadır.

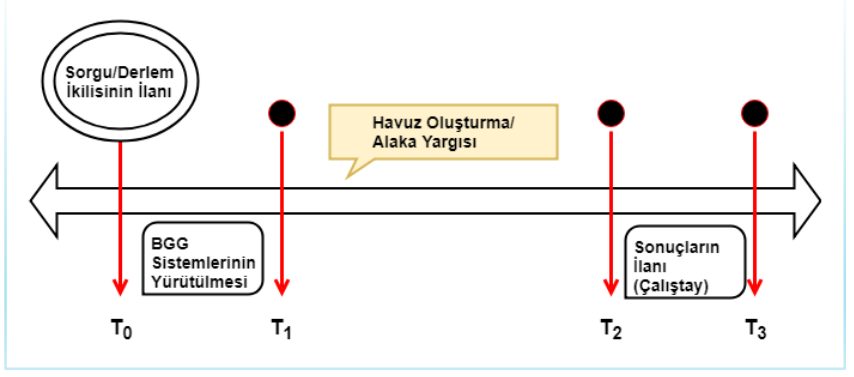

Şekil 1. TREC organizasyon süreci

Aslen, her bir TREC izi sonunda yeni bir test veri kümesi hazırlanmış olmaktadır. İlgili test materyalleri üç bileșenden olușmaktadır.

[1] Derlem, bir belge topluluğu.

[2] Sorgu kümesi, bilgi ihtiyacını tanımlayan ifadeler.
[3] Alaka yargıları kümesi, her sorgu belge çifti için alakalı veya alakasız yargısını gösteren değerlendirmeler.

Genellikle derlemler standart olmakla birlikte farklılık sorgularla sağlanmaktadır. Örnek olarak web izi için 2012'ye kadar ClueWeb09 derlemi 
kullanılırken[19], sonraki izlerde daha büyük boyutlu yeni bir derlem olan, ClueWeb12 kullanılmıștır [20]. Yani, bugüne kadar gerçekleştirilen çok sayıdaki TREC izine karşılık kullanılan derlem çeşitliliği oldukça kısıtlıdır. Sorgu kümelerinin oluşturulması ise yönetimsel karmaşıklık ve yoğun iş hacminden çok, gerçek sorgu uzayına yakın veya benzer olmasına yönelik uzmanlık isteyen bir süreçtir. Aksine alaka yargıları kümesinin hazırlanması doğru yönetilmesi gereken yoğun bir iş yükü oluşturmaktadır. Binlerce sorgu-belge çiftinin alakalı/alakasız olarak değerlendirilmesi ancak çok sayıda değerlendime uzmanı/hakem tarafindan yapılabilmektedir. $\mathrm{Bu}$ değerlendirmelerin gerçeklenmesi ve sonuçlarının toplanması için doğal olarak dijital ortamda bir yönetim otomasyonuna ihtiyaç vardır. Şekil 1'de gösterilen T1 ve T2 zaman aralıklarında yapılan havuz oluşturma ve alaka yargısı yapılması işlemleri çalışmada geliştirilen araç ile yapılabilmektedir.

\section{Uygulama Tasarımı}

\subsection{Geliştirme çatısı ve teknolojiler}

Geliștirme çatısı olarak NODE.JS kullanılmıștır. NODE.JS açlk kaynak kodlu olup, JavaScript tabanlıdır. Ayrıca paket yönetim sistemiyle, bağlantılı modülleri kolayca ekleyip çlkarabilmeyi sağlamaktadır. NODE.JS'in bir diğer avantajlarından biri de modülerliktir. Kolayca taşınabilir ve çalıșır hale getirebilir bir geliştirme çatısıdır.

Oturum açma, oturum yönetimi gibi durumlar için yine bir NODE.JS modülü olan EXPRESS.JS kullanılmıştır. EXPRESS.JS oturum yönetimi için bir ara katman yazılımıdır. EXPRESS.JS sunucuya gelen istekleri doğrulama, hata yazdırma gibi özelliklere sahiptir. Gösterim motoru olarak HANDLEBAR.JS kullanılmıștır. HANDLEBAR.JS JavaScript dilleri için geliştirilmiş bir şablon motorudur. Sunucu taraflı ve istemci taraflı kullanılabilmektedir.

Veri tabanı olarak NoSQL teknolojisine uygun olan MongoDB seçilmiștir. Bașlıca nedenlerinden biri açık kaynak kodlu olup ücretsiz olmasıdır. NoSQL teknolojisini geleneksel SQL teknolojisinden ayıran en temel unsur unrelational yani bağlantısız veri tabanları olușturulabilmesi, böylece tablo sayısını daha az tutmaya olanak sağlamasıdır.
Projede kullanılan bir diğer teknoloji ise Sunucu Gönderimli Olay'dır (İng. Server Sent Event, kıs. SSE). SSE, sunucudan istemci tarafına, web soket mantığında mesaj göndermeyi sağlayan bir teknolojidir. Bunun için ek bir modül kullanılmamış, doğal JavaScript yöntemleriyle sağlanmıștır. Ayrıca proje versiyon kontrolü için GIT teknolojisinden yararlanılmıştır ve kaynak kodlar dışardan erişime açık şekilde github.com sunucularında saklanmıștır.

\subsection{Yazılım tasarımı}

Yazılım çatısı olarak NODE.JS teknolojisinin kullanıldığı sistemde, ana programlama dili JavaScript'tir. NODE.JS çatısının tercih edilmesindeki ana sebeplerden birkaçı ise, platform bağımsız çalışabilen, etkin veri akıșı sağlayan, açık kaynak kodlu bir teknoloji olmasıdır. Açık kaynak kodlu oluşu, dünya genelinde milyonlarca geliștirici tarafından desteklenmesi ve herhangi bir sorun karşısında kolay bir șekilde çözüm bulanabilmesi gibi avantajları beraberinde getirmektedir. NODE.JS, diğer geleneksel internet uygulamalarının aksine olay-tabanlı (İng. event-driven) çalışabilmektedir. Geleneksel internet uygulamaları kullanıcının bir istek yapmasıyla tetiklenirken, NODE.JS de bu olay-tabanlı olup, sunucu taraflı isteklerle de tetiklenebilmektedir. $\mathrm{Bu}$ da daha etkileşimli (İng. interactive) internet uygulamaları tasarlamaya olanak sağlamaktadır.

NODE.JS yazılım çatısındaki temel özelliklerden biri değişik eylemler için farklı yönlendirmeler yapıp, böylece diğer betik (İng. script) tabanlı mimarilere göre daha modüler bir yapı sağlamasıdır. Tasarım mimarisinde ilk olarak ele alınan problem, sisteme giriș, çıkıș ve kullanıcı tanımlamalarıdır. Uygulamaya giriş ve çıkıș işlemleri, kullanıcı kayıtları ana dizin altındaki USER.JS tarafından yönetilmektedir. Şekil 2'de görüldüğü gibi kullanıcı doğrulamaları, şifre sıfırlamaları, sistemden giriș, çıkış gibi eylemler bu betik grubunda yönetilmiştir.

Mimarideki bir diğer ana yönlendirme ise, sistemdeki rol durumuna göre doğrulanmış kullanıcıların farklı dizinlere yönlendirilmesidir. Uygulamada iki temel rol vardır; yönetici ve normal kullanıcı. Sisteme başarıyla giriş yapan kullanıcılar, veri tabanındaki rol bilgisine göre ana dizin altındaki ADMIN ya da USER dizinine yönlendirilir. $\mathrm{Bu}$ aynı zamanda geliștirici tarafında da kodlama esnasından daha temiz bir okuma sağlamaktadır. ADMIN rolündeki 
kullanıcıların; veri yürütümü yaratma, sorgu kümesi yükleme, daha önceden yaratılan yürütümler için atama gibi işlemleri bu dizin grubundaki ADMIN.JS betik dosyası tarafindan yönetilmektedir. Aynı zamanda normal kullanıcı rolündeki kullanıcıların; atanmıs yürütüm detayını görüntüleme, atamalar için alakalı yargısını işaretleme gibi işlemleri de yine ADMIN.JS betik dosyası tarafından yönetilmektedir.

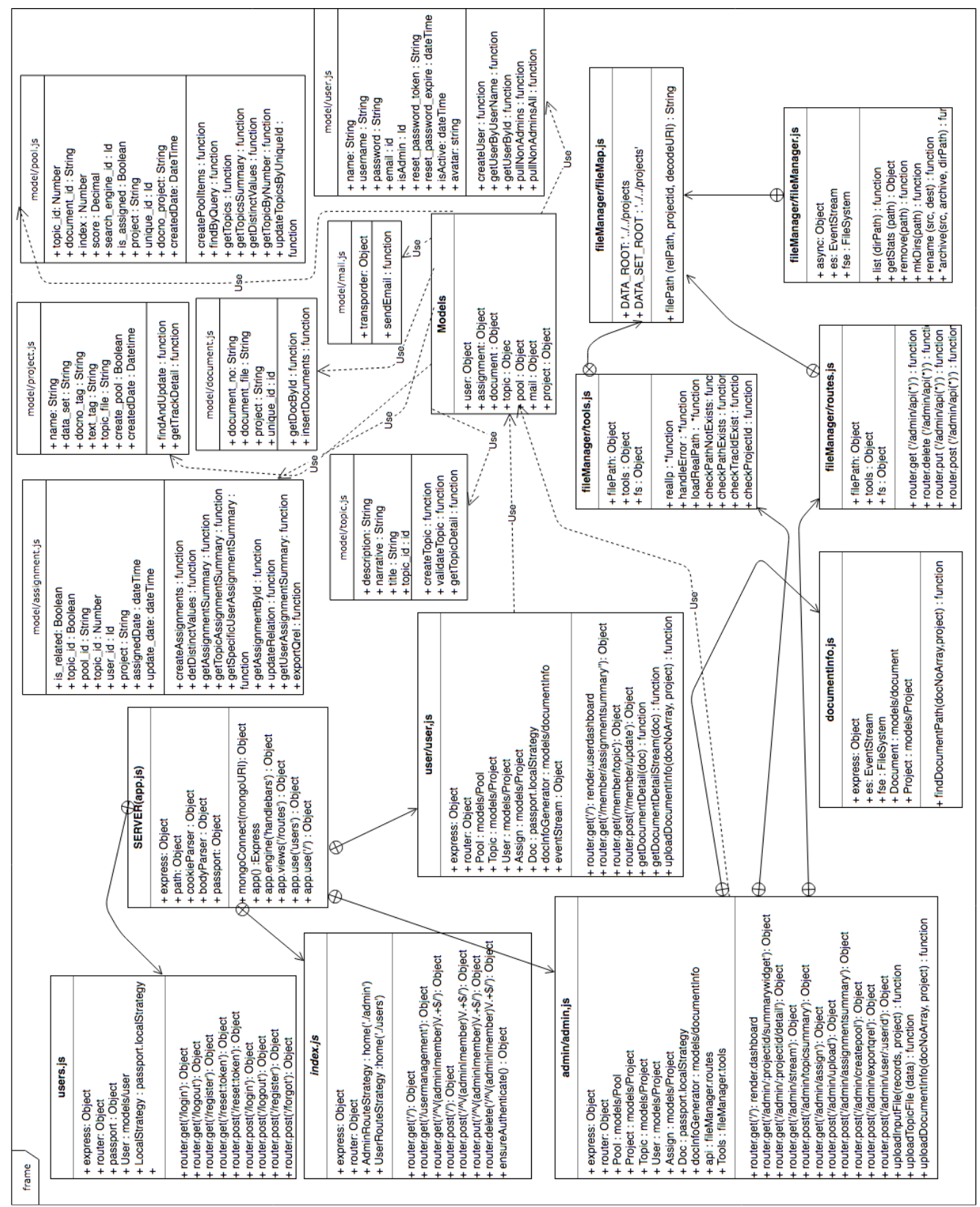

Şekil 2. Araç UML Şeması

Mimaride iki ana alt grup daha vardır. Bunlar FILEMANAGER ve MODEL dizinleridir. Bunlardan FILEMANAGER, dosya ve dizin işlemlerinin ayrıștırılması, MODEL grubu ise, kayıtların veri tabanına kayıtlanmadan önce bir ara yüz yaratılması amacıyla tasarlanmıştır. 
FILEMANAGER dizini altındaki betik dosyaları, ADMIN rolündeki kullanıcıların, veri kümelerini görüntüleme, veri yürütümü için dosya açma silme gibi yerel dosyalama işlemlerini gerçekleştirmesi gibi işlemleri sağlamaktadır.

MODEL dizini ise, yukarıda belirtildiği üzere veri tabanı kayıtlarına bir ara yüz sunmaktadır (DATA-LAYER). Bu sinıflar veri tabanı tablolarının bir yansıması gibi düşünülebilir. MODEL dizini altında; kullanıcı (USER), proje (PROJECT), havuz (POOL), döküman (DOCUMENTS), konu (TOPIC), atama (ASSIGNMENT) ve posta (MAIL) ara sinıflarını görmek mümkündür. Posta sınıfı hariç diğer bütün sınıflar veri tabanı tablolarının birer kopyasıdır. $\mathrm{Bu}$ sinıflarda verilen bilginin doğrulanması ve kayıt alanlarının hangi tipte tanımlamalar kabul ettiği gibi bilgiler tutularak, bilgi bütünlüğü ve doğruluğunu sağlamak amaçlanmıştır.

\subsection{Veri tabanı tasarımı}

Sistemde temel anlamda kullanıcılar dıșında beș öğe bulunmaktadır: izler, belgeler, konular, havuzlar ve atamalar; Şekil 3'te gösterilen veritabanı șemasında bunlar sırasıyla "tracks", "documents", "topics", "pools" ve "assignment" tabloları ile belirtilmiștir. Bütün hiyerarşinin başında izler bulunmaktadır. Temel olarak bir izi oluşturan veriler onun numarası, adı, oluşturma tarihi, belge topluluğu, belge numaraları ile metnin yerini gösteren XML etiketleri ve sorgu kümesidir. Bunlardan "belge topluluğu" ve "sorgular" ayrı tablolar olarak tasarlanmıștır; TREC standartlarında sorgu "topic" olarak adlandırıldığından bu ifade kullanılmıştır. Belge topluluğunun kök dizin yolu ise izler'e eklenmiştir.

Havuzlarda ise her izde gerçekleștirilen yürütümlerdeki belge ve sorgu ikilileri tutulmaktadır. Bu ikililer birden fazla yürütüm sonucundan aynı gelebilecekleri için RunID ile yürütümler gösterilmektedir. Ayrıca isAssigned ile ilgili dokümanın bir değerlendiriciye atanıp atanmadı̆̆ havuzdaki belgelerin kullanıcılara atanmasına ilișkin bilgiler mevcuttur. Kullanıcılar, aslen değerlendirici/hakem olan varlıklardır. Kendilerine atanan belgelerin değerlendirilmesi ise isRelated özelliğiyle sağlanmaktadır. $\mathrm{Bu}$ özellik null değeri alabilmektedir: Böylece değerlendirme işleminin gerçekleşip gerçekleşmediği anlaşılabilmektedir.

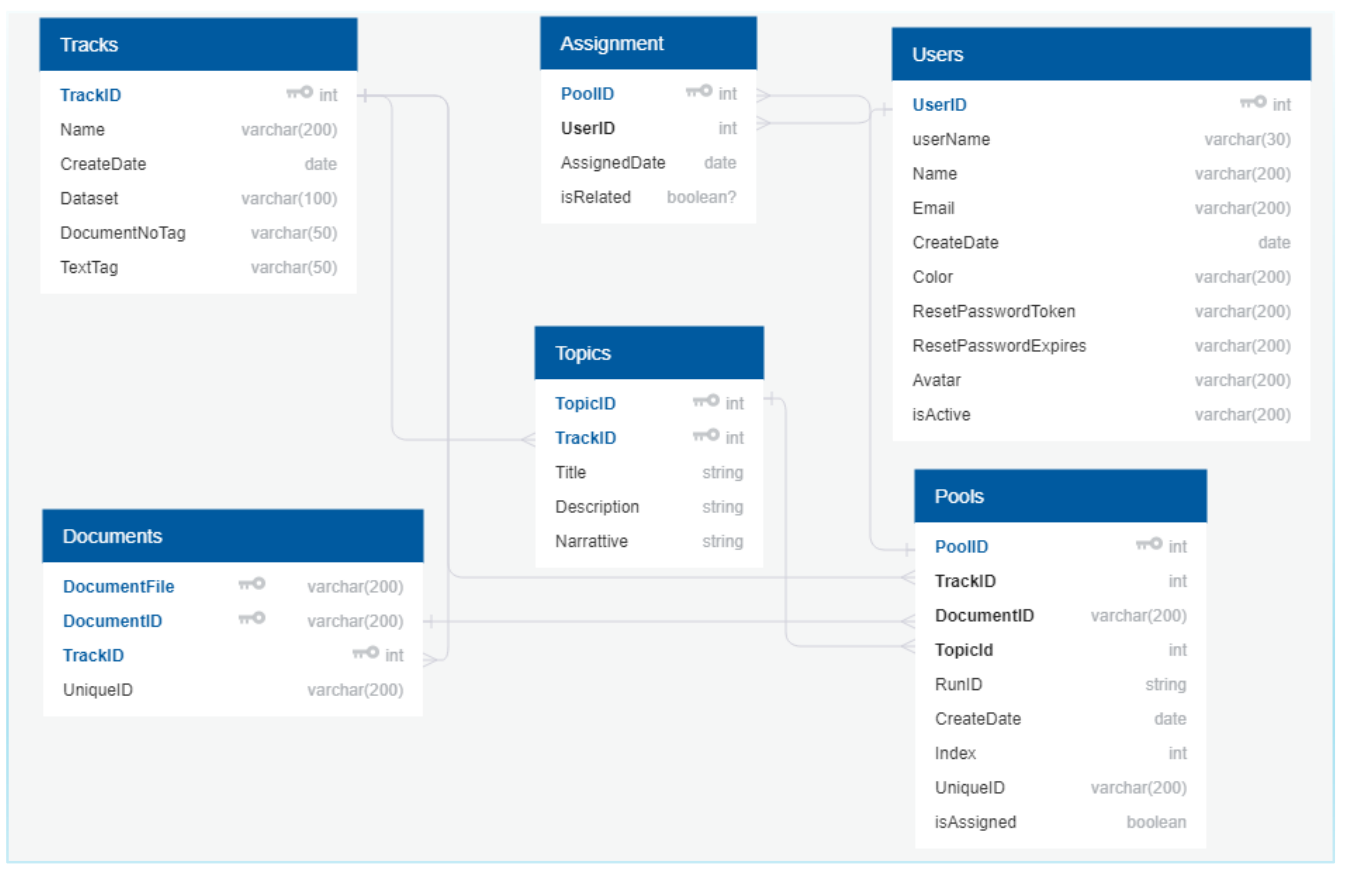

Şekil 3. Veritabanı şeması 


\section{Sistem Kullanım Akışı}

Sistemde kayıtlı iki tip kullanıcıdan yönetici ve değerlendirici/hakem işlemleri açısından geliştirilen sistemin akış şeması Şekil 4'te verilmiștir. İlk olarak, yönetici haklarına sahip kullanıcı tarafindan belge topluluğu ve sorgu kümesi seçerilerek yeni bir iz oluşturulmaktadır. İlgili ize ait yürütüm sonuçları ancak bu aşamadan sonra yüklenebilmektedir. Bu iki aşamanın başarıyla tamamlanmasından sonra ise değerlendirilecek belgelerin bulunduğu havuz oluşturulabilmektedir. İz yöneticisi, sistemde kayıtlı hakem haklarına sahip kullanıcılara bu havuzdan istediği belgeleri atayabilmekte veya atanmış belgeleri tekrar havuza alabilmektedir.

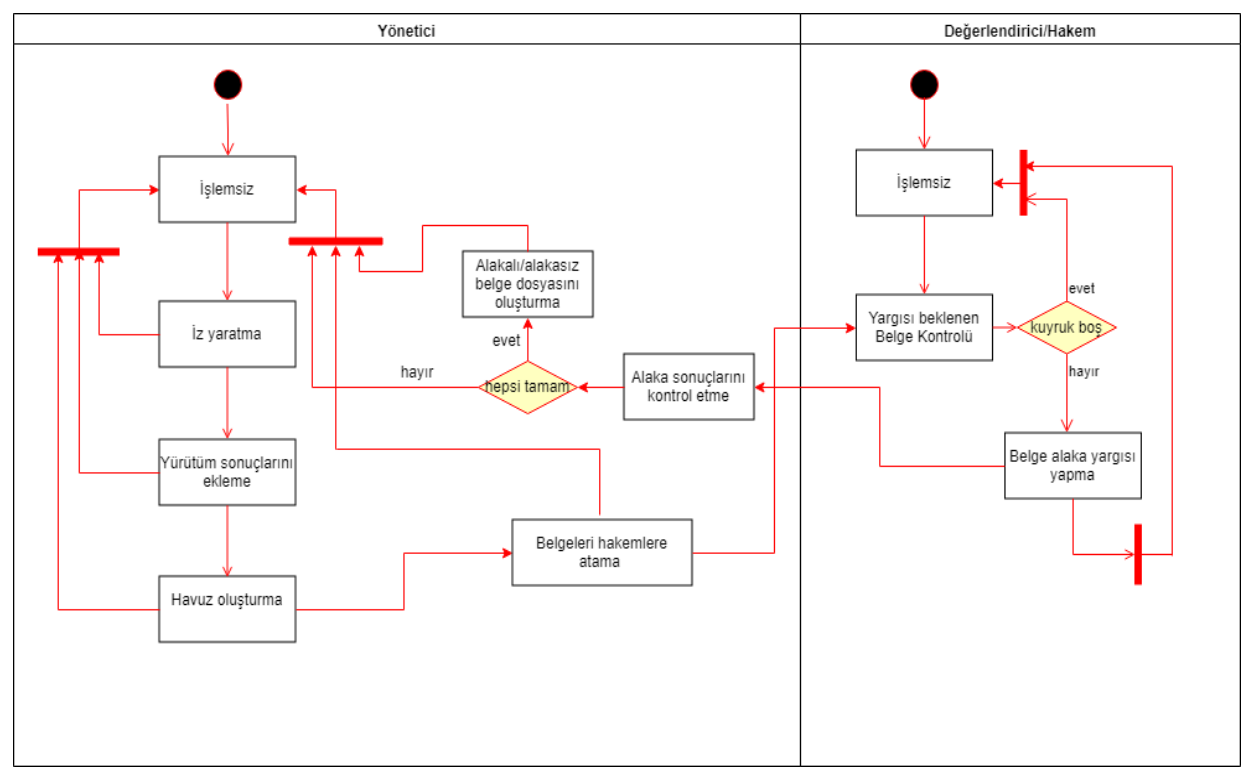

Şekil 4. Sistem akış şeması

Hakem ise kendine atanmıș olan belgelerin olup olmadığını kontrol edebilmekte ve eğer alaka yargısını yapmadığı bir belge mevcut ise değerlendirme sürecini başlatabilmektedir. Belge değerlendirim sonucunu sisteme girerse, sistem tarafından tüm havuzun değerlendirilip değerlendirilmediği kontrol edilmektedir. Eğer havuzdaki belgelerin hepsi alakalı/alakasız olarak işaretlenmiş ise TREC standartlarında belirtilen sonuç dosyası otomatik olarak olușturulmaktadır.

\section{Tartışma ve Sonuç}

Bu çalışmada geliştirilen araç ile anlık sorgu geri getiriminde kullanılabilecek test veri kümesinin oluşturulması hızlandırılarak süreç yönetilebilir hale getirilmiştir. Türkçe metinlerin geri getirimi üzerine yapılan çalışmaların test edilebileceği standartlara uygun tek $\mathrm{BE}$ veri kümesi BilCol2005 deney koleksiyonudur[21]. Ancak BE çalışmalarının gelişmesi ve ilerlemesi için yenilerine ihtiyaç vardır. Büyük ölçekli BE sistemlerini değerlendirmeyi hedefleyen TREC ve benzeri kuruluşlar bu çeşitliliği sağlayarak doğru sonuçlara ulaşmayı amaçlamaktadır.

Özetle, Türkçe yazılı derlemler için TREC benzeri bir çalıştayın sürdürülebilir halde gerçekleştirilmesi BE çalışmalarının artması için çok önemlidir. TREC'in temel aldığı havuzlama (ing. Pooling) mekanizması, farklı katılımcllardan/sistemlerden gelen yürütüm sonuçlarına ihtiyaç duymaktadır. Doğal olarak böyle bir süreçte sistem performanslarının katılımcllara geri bildirilmesi gerekmektedir. Gelecek çalışmalarda alaka yargısı yapmayı sağlayan bu araca ilgili izdeki sistem başarımlarını değerlendirmeye yönelik bir eklenti yapılması planlanmaktadır. $\mathrm{Bu}$ sayede, Türkçe $\mathrm{BE}$ için düzenlemeyi düşündüğümüz çalıştay teknik anlamda tam otomatik hale gelecektir; yani çalıştay ile ilgili tüm süreçler dijital ortamda gerçekleştirilecektir. 
DEÜ FMD 23(67), 277-284, 2021

\section{Teşekkür}

$\mathrm{Bu}$ proje Ege Üniversitesi Bilimsel Araștırma Projeleri Koordinasyon Birimi tarafından 18-UBE-001 proje numarası ile desteklenmiştir.

\section{Kaynakça}

[1] Chapelle, O., Metlzer, D., Zhang, Y., Grinspan, P. 2009 Expected reciprocal rank for graded relevance. In Proceedings of the 18th ACM Conference on Information and Knowledge Management, 621-630.

[2] Järvelin, K., Kekäläinen, J. 2002. Cumulated gainbased evaluation of IR techniques. ACM Transactions on Information Systems (TOIS), 20(4):422-446.

[3] Clarke, C.L.A., Kolla, M., Cormack, G.V., Vechtomova, O., Ashkann, A., Buttcher, S., MacKinnon, I. 2008. Novelty and diversity in information retrieval evaluation. In Proceedings of the 31st Annual International ACM SIGIR Conference on Research and Development in Information Retrieval, 659666.

[4] Agrawal, R., Gollapudi, S., Halverson, A., Ieong, S 2009. Diversifying search results. In Proceedings of the Second ACM International Conference on Web Search and Data Mining, 5-14.

[5] Cleverdon, C. 1967. The Cranfield tests on index language devices. Aslib proceedings, 19(6), 173194.

[6] TREC web sayfası. http://trec.nist.gov/ (Erişim Tarihi: 14/12/2018).

[7] Lew, M. S., Sebe, N., Djeraba, C., Jain, R. 2006. Content-based multimedia information retrieval: State of the art and challenges. ACM Transactions on Multimedia Computing, Communications, and

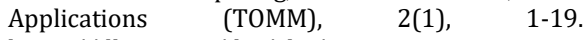
https://dl.acm.org/doi/abs/ $10.1145 / 1126004.1126005$

[8] Sanderson, M., 2010. Test Collection Based Evaluation of Information Retrieval Systems. Foundations and Trends® in Information Retrieval, 4(4), 247-375. DOI: 10.1561/1500000009

[9] Harman, D. 1992. Overview of the First Text REtrieval Conference (TREC-1). NIST Special Publication 500-207: The First Text Retrieval Conference Proceedings (TREC-1), 1-20.

[10] Harman, D. 1993. Overview of the Second Text REtrieval Conference (TREC-2). NIST Special Publication 500-215: The Second Text Retrieval Conference Proceedings (TREC-2), 1-20.

[11] Harman, D. 1994. Overview of the Third Text REtrieval Conference (TREC-3). NIST Special Publication 500-225: The Third Text Retrieval Conference Proceedings (TREC-3), 1-20.

[12] Voorhees, E.M. 2007. Overview of TREC-2007. NIST Special Publication 500-274: The 16th Text Retrieval Conference Proceedings (TREC 2007), 1-17.

[13] TREC-COVID Challenge web sayfası https://ir.nist.gov/covidSubmit/ (Erişim Tarihi: 02/07/2020).

[14] TREC-2019 Deep Learning Track web sayfası. https://trec.nist.gov/data/ deep2019.html (Erişim Tarihi: 02/07/2020).
[15] Hintçe için bilgi erişim görevleri içeren forum. web sayfası. http://fire.irsi.res.in/fire/2019/home (Erişim Tarihi: 02/07/2020).

[16] Çince için bilgi erişim görevleri içeren web sayfası. http://www.thuir.cn/ntcirwww2/ (Erişim Tarihi: 02/07/2020).

[17] Rusya bilgi erişim değerlendirme semineri web sayfası. http://romip.ru/en/ (Erișim Tarihi: 02/07/2020).

[18] Voorhees, E.M. 2007. TREC: Continuing information retrieval's tradition of experimentation. Communications of the ACM. 50(11), 51-54. DOI:10.1145/1297797.1297822

[19] Clarke, C.L.A., Craswell, N., Soboroff, I. 2012. Overview of the TREC 2012 Web track. 21 th Text REtrieval Conference, Gaithersburg, Maryland.

[20] Collins-Thompson, K., Macdonald, C., Bennett, P., Diaz, F., Voorhees, E.M. 2014. TREC 2014 web track overview. $23^{\text {th }}$ Text REtrieval Conference, Maryland.

[21] Can, F., Kocberber, S., Balcik, E., Kaynak, C., Ocalan, H.C., Vursavas, O.M. 2008. Information retrieval on Turkish texts. Journal of the American Society for Information Science and Technology 59(3), 407 421. DOI: 10.1002 /asi.20750 